\title{
Screening for Abdominal Aortic Aneurysms and Risk Factors in 65-Year-Old Men in Oslo, Norway
}

\author{
Toril Rabben' \\ Saira Mauland Mansoor ${ }^{\prime}$ \\ Dag Bay ${ }^{2}$ \\ Jon Otto Sundhagen (ID) \\ Cecilia Guevara' \\ Jorgen Joakim Jorgensen 1,3,4 \\ 'Department of Vascular Surgery, Oslo \\ University Hospital, Oslo, Norway; \\ ${ }^{2}$ Department of Radiology and \\ Interventional Radiology, Oslo University \\ Hospital, Oslo, Norway; ${ }^{3}$ Department of \\ Traumatology, Oslo University Hospital, \\ Oslo, Norway; ${ }^{4}$ Institute of Clinical \\ Medicine, Faculty of Medicine, University \\ of Oslo, Oslo, Norway
}

Correspondence: Toril Rabben

Department of Vascular Surgery, Oslo

University Hospital, P.O. Box 4950

Nydalen, Oslo, 0424, Norway

Tel +47 9719098I

Email torabb@ous-hf.no
Purpose: To investigate the prevalence of and risk factors for abdominal aortic aneurysm (AAA) in 65-year-old men in Oslo, Norway.

Materials and Methods: From May 2011, until September 2019, the annual population of 65year-old men living in Oslo were invited to an ultrasonographic screening of the abdominal aorta. Candidates received a one-time invitation by mail, including a questionnaire on possible risk factors and comorbidities. Abdominal aortic outer-to-outer diameter and ankle-brachial index were measured by the screening team. Participants were allocated into three groups: non-, suband aneurysmal aorta. Written information on recommended follow-up regime was given to participants with an aortic diameter $\geq 25 \mathrm{~mm}$. Univariate and multivariate analyses of potential risk factors were performed, in addition to descriptive analyses and significance testing.

Results: In total, 19,328 were invited, 13,215 men were screened, of which 12,822 accepted inclusion in the study. Aortic diameter was registered for 12,810 participants and 330 men had aortic diameter $\geq 30 \mathrm{~mm}$, giving a prevalence of AAA of $2.6 \%$ (95\% confidence interval (CI) 2.31-2.86). We identified 4 independent risk factors for AAA: smoking (OR $=3.64$, 95\% CI 2.90-4.58), hypertension ( $\mathrm{OR}=1.87,95 \%$ CI 1.49-2.35), BMI $>30(\mathrm{OR}=1.02$, 95\% CI 1.00-1.03), and diabetes mellitus ( $\mathrm{OR}=0.52,95 \% \mathrm{CI} 0.35-0.79)$, the latter showing an inverse association with AAA growth. A subgroup of 862 men with aortic diameters 25 $29 \mathrm{~mm}$ had a significantly higher prevalence of BMI $>25$, smoking and family history of AAA, compared to participants with aortic diameter $<25 \mathrm{~mm}$.

Conclusion: Among the participants in this study, the prevalence of abdominal aortic aneurysms was $2.6 \%$. Participants with AAA more frequently reported cardiovascular risk factors, and less frequently diabetes mellitus.

Keywords: prevalence, sub-aneurysmal aorta, ultrasonography, men, smoking, diabetes

\section{Plain Language Summary}

This is a population-based screening study of the abdominal aorta in 65-year-old men in Oslo. Ultrasonographic screening of the abdominal aorta was offered to all 65-year-old men living in Oslo, Norway. In a population of 12,810 men, 330 cases of abdominal aortic aneurysms (AAA) were found, giving a prevalence of $2.6 \%$.

Compared with studies from the $80 \mathrm{~s}$ and $90 \mathrm{~s}$, this study revealed a lower prevalence of abdominal aortic aneurysms in 65 -year-old men. This prevalence is nonetheless twice as high as that reported in recent studies $(1.3-1.5 \%)$. Four risk factors for AAA were identified: smoking, hypertension, body-mass index (BMI) $>30$ and diabetes mellitus, the latter having an inverse effect on AAA growth. In addition, there was a significantly higher prevalence of peripheral artery disease and a history of stroke amongst participants with AAAs. Since the presence of AAA is a potential life-threatening condition, screening is an important tool in early detection of the disease. 


\section{Introduction}

Abdominal aortic aneurysm is a potentially lethal condition, most prevalent in elderly men. Ruptured AAA (rAAA) has a high mortality rate. A nationwide analysis of rAAA in Portugal has shown that approximately $75 \%$ of patients with rAAA die before reaching hospital or during hospitalization. ${ }^{1}$ Budtz-Lilly et al have reported a perioperative mortality for emergency surgery at $28.8 \%{ }^{2}$ Furthermore, the 30-day mortality ranges from around $30-60 \% .^{1,3-5}$ In contrast, mortality rates for elective AAA surgery are drastically lower, 30-day mortality range from $0.5 \%$ to $5.0 \%{ }^{6-9}$

Several large studies have shown that one-time ultrasound screening in men above 65 years reduces the incidence of sudden AAA ruptures and aneurysm-related mortality. ${ }^{9-15}$ Consequently, Sweden (2006) and the United Kingdom (2009) have implemented national screening programs for ultrasonographic detection of AAA. ${ }^{9,16}$ In the United States, one-time screening for AAA has been offered since 2007 to male members of Medicare between the ages of 65 to 75 years with any history of smoking. ${ }^{17}$

In Sweden, the prevalence of AAA in 65-year-old men is $1.5 \%{ }^{9}$ The national screening program in the United Kingdom has shown a AAA prevalence in $\geq 65$-year-old men at $1.57 \%{ }^{16}$ A study from the United States found a prevalence of AAA in the population aged 50 to 84 years (both men and women) of $1.4 \%{ }^{18}$ This is in contrast to results from earlier studies from the $80 \mathrm{~s}$ and $90 \mathrm{~s}$, which demonstrated a prevalence of 4.0-9.0\%. ${ }^{19-22}$ Data from the Gloucestershire Aneurysm Screening Program also reveal a decline in AAA prevalence in 65-year-old men, from $5.0 \%$ in 1991 to $1.3 \%$ in $2015 .^{23}$

Krohn et al examined 500 Norwegian men above 60 years in 1992, and found that 5.8\% had small and $2.4 \%$ had large AAAs. ${ }^{24}$ In 2001, Singh et al found a AAA prevalence of $8.9 \%$ in 23-84-year-old men in the Tromsø study, in Norway. ${ }^{25,26}$ To our knowledge, there are no other studies on the prevalence of AAA in Norway, and there are no national or regional screening programs for AAA in Norway. The aim of the present study was to examine the current prevalence and risk factors for AAA in 65-year-old men in Oslo. We hypothesize that the prevalence may be lower than previously reported.

\section{Materials and Methods}

From May 2011, annually all 65-year-old men with permanent residence in Oslo were invited (one-time invitation by mail) to undergo an ultrasonography of the abdominal aorta. Names, dates of birth and contact information were extracted from the National Population Register. The invitation included a questionnaire on potential risk factors for and comorbidities with AAA, which was completed in collaboration with the screening team on the day of screening. The screening was performed in the outpatient clinic of the Department of Vascular Surgery at Oslo University Hospital.

The screening team consists of radiographers and nurses with special training in abdominal aorta ultrasonography. Their training was given by a consultant radiologist from the Department of Radiology and Interventional Radiology at Oslo University Hospital. The screening team has been consistent throughout the screening period. In the early phase, the consultant radiologist did sample tests to validate the ultrasonographic results. Ultrasonography of the abdominal aorta is a highly sensitive and specific modality for detection of AAAs. ${ }^{11,27,28}$

The screening team works at the Department of Vascular Surgery and the Department of Radiology and Interventional Radiology at Oslo University Hospital, and the costs were shared between these two departments. The screening project has no external funding.

The examinations were performed with a sector probe (Sonix SP; C5-2 probe, Ultrasonix). The aorta was examined in the axial plane with scans perpendicular to the longitudinal plane. The maximum aortic diameter was measured below the level of the renal arteries from the outer-to-outer (OTO) wall with electronic calipers, both in the transverse and anterior-posterior plane. The highest of these measurements was used. OTO is considered the most reliable diameter of the aorta. ${ }^{29}$ The sensitivity of the method was ensured consecutively through instrument calibration by an experienced radiologist. A biomedical scientist consecutively collected the data in a database (FileMaker Pro 14).

The internationally accepted definition of AAA was used; diameter of $\geq 30 \mathrm{~mm} .{ }^{30}$ Written information on recommended follow-up regime was given to participants with an aortic diameter $\geq 25 \mathrm{~mm}$. Follow-up until aortic diameter $45 \mathrm{~mm}$ is facilitated by the general practitioner. At aortic diameter $\geq 45 \mathrm{~mm}$, participants are referred to the Department of Vascular Surgery for further follow-up and eventually treatment (Figure 1). In Norway, all citizens are entitled to a dedicated general practitioner, as part of the public healthcare system.

The ankle- and brachial pressures were measured in both arms and both legs (both dorsalis pedis artery and posterior tibial artery) for each participant, by 


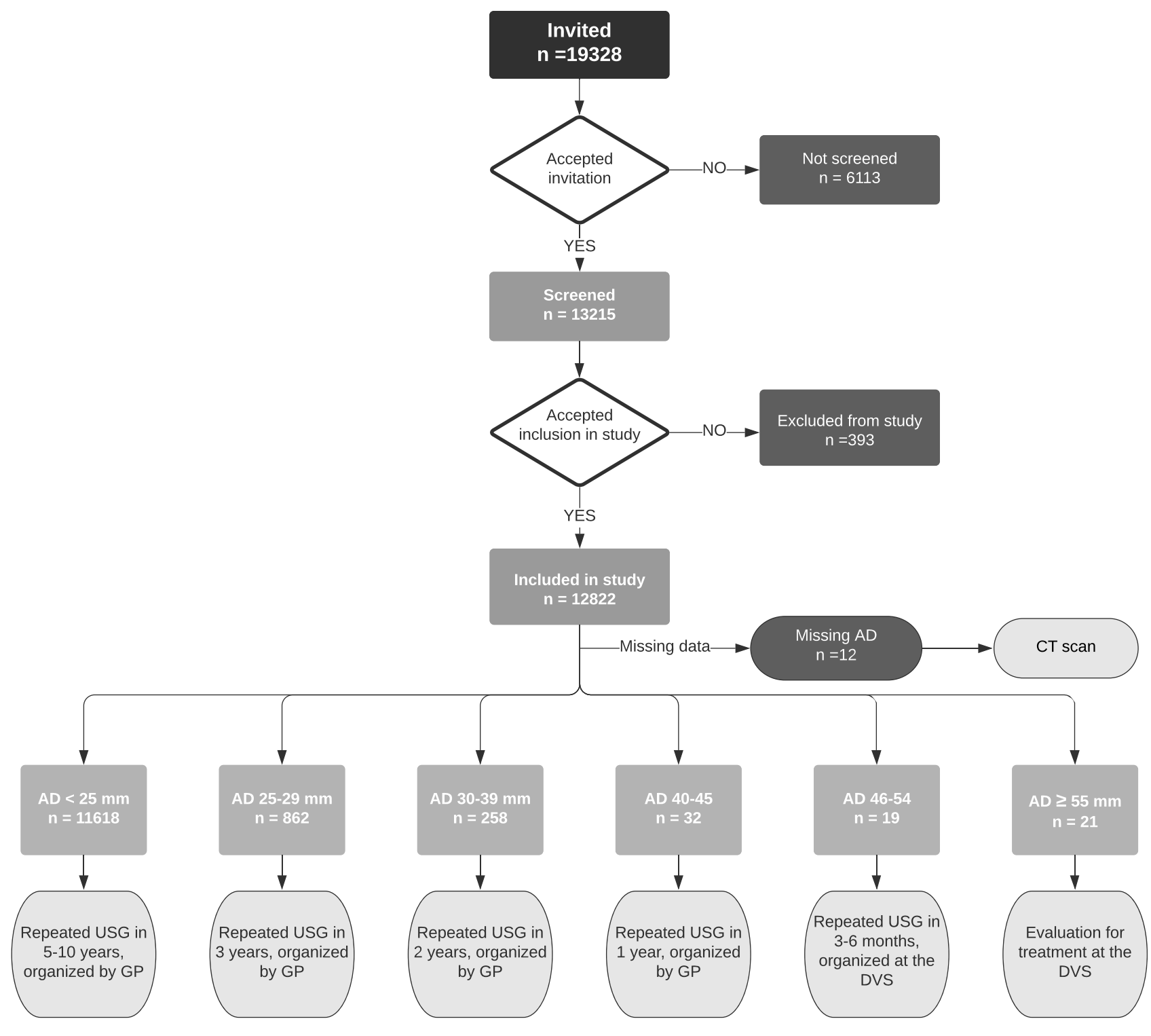

Figure I Consort diagram. The diagram shows the allocation of the invited candidates, distribution of aortic diameters, and recommended follow-up regime depending on measured aortic diameter.

Abbreviations: AD, aortic diameter; USG, ultrasonography; GP, general practitioner; DVS, Department of Vascular Surgery.

sphygmomanometry using a Doppler ultrasound transducer. The highest of the two systolic ankle pressures was taken as the numerator for each leg and the highest systolic brachial pressure as the denominator for the arm. An ankle-brachial index $(\mathrm{ABI})<0.9$ in either leg is considered abnormal and indicates peripheral artery disease (PAD). ${ }^{31}$

Statistical analyses were performed using SPSS (ver. 26). The program was used for descriptive analyses, categorical data including frequency values, tables and histograms for evaluation of normal distribution. Crosstabs were used to examine the distribution of variables, and Pearson's chi square test was used for significance testing. Statistical significance was set at $\mathrm{p}$-value $\leq 0.05$.
In the univariate analysis, contingency tables were used for the discrete variables and Student's $t$-test for continuous variables. The logistic model was used in the multivariate analysis to pinpoint independent risk factors of AAA. The predictive accuracy of the model was evaluated by calibration and discrimination. Calibration, which measures the ability of the logistic model to assign the appropriate risk, was evaluated by the Hosmer and Lemeshow (H-L) goodness-of-fit test. The H-L measures the difference between expected and observed outcomes over deciles of risk. A statistically not significant H-L result (p-value $>0.05$ ) suggests that the model predicts accurately on average. Discrimination, which measures the ability of the model to 
differentiate among those who have or do not have AAA, was evaluated by the analysis of the area under the receiver operating characteristic (ROC) curve. If the area under the curve is greater than 0.7 it can be concluded that the model has an acceptable discriminatory capability. ${ }^{32}$

The study was approved by the Regional Committees for Medical and Health Research Ethics (REC reference number 2009/866) and complies with the Declaration of Helsinki. Informed consents were obtained from all participants in writing. The study is registered at https://clini caltrials.gov/show/NCT01248533.

\section{Results}

In total, 19,328 were invited, 13,215 men were screened, and 12,822 were included in the study. Of these, 12 participants were excluded due to missing data on aortic diameter, leaving 12,810 eligible for statistical analyses (Figure 1). For the 12 excluded participants, aortic diameter was not possible to obtain due to lack of ultrasonographic visibility for any reason (the participants were also examined by an experienced radiologist). These participants were further examined with a CT scan. The recorded aortic diameters for the participants were normally distributed. Annually, 1124-2784 men were invited (the lowest number represents the first year of screening, that is from May 2011), of which $63.3-77.6 \%$ accepted the invitation, and participation rate increased during the study period (Figure 2).

The mean aortic diameter in the studied cohort was $22.1 \mathrm{~mm}$ (SD $3.5 \mathrm{~mm}$ ), and the AAA prevalence was $2.6 \%$ (95\% CI 2.31-2.86). Figure 2 illustrates the annual prevalence of AAA during the study period. The distribution of aneurysm-size is shown in Figure 3.
Participants with AAA had significantly higher prevalence of $\mathrm{BMI}>25$, hypertension, intermittent claudication (IC), and $\mathrm{ABI}<0.9$, than participants with normal aortas (Table 1). More often, candidates with AAA reported a history of previous myocardial infarction (MI) or stroke, current smoking, and a family history of AAA. More participants with AAA were using statins and acetyl salicylic acid (ASA) than participants with normal aortic diameter. There was no statistical difference between participants with or without AAA on history of transient ischemic attack (TIA) or previous smoking. There was a higher, but not statistically significant, prevalence of diabetes mellitus amongst participants without aneurysms (Table 1).

Performing regression analyses, we found four independent risk factors for AAA: smoking, hypertension, obesity $($ BMI $>30)$ and diabetes mellitus. Smoking was the most important risk factor (Tables 2 and 3). The ROC curve is presented in Figure 4.

Sub-aneurysmal aortas $(25-29 \mathrm{~mm})$ were found in $6.7 \%$ of the participants. These participants more often presented with risk factors such as BMI $>25$, stroke, current smoking and family history of AAA, but less often diabetes mellitus, when compared to the group with aortic diameter $<25 \mathrm{~mm}$ (Table 1 ).

\section{Discussion}

This study revealed a AAA prevalence of $2.6 \%$ in the screened population of 65 -year-old men living in Oslo. This is much lower than large screening studies from the 80 s and 90s, and twice as high as recent findings in Sweden and the United Kingdom. ${ }^{9,16,19-23,33}$

The target population was invited one time only, achieving an annual participation rate up to $77.6 \%$. This

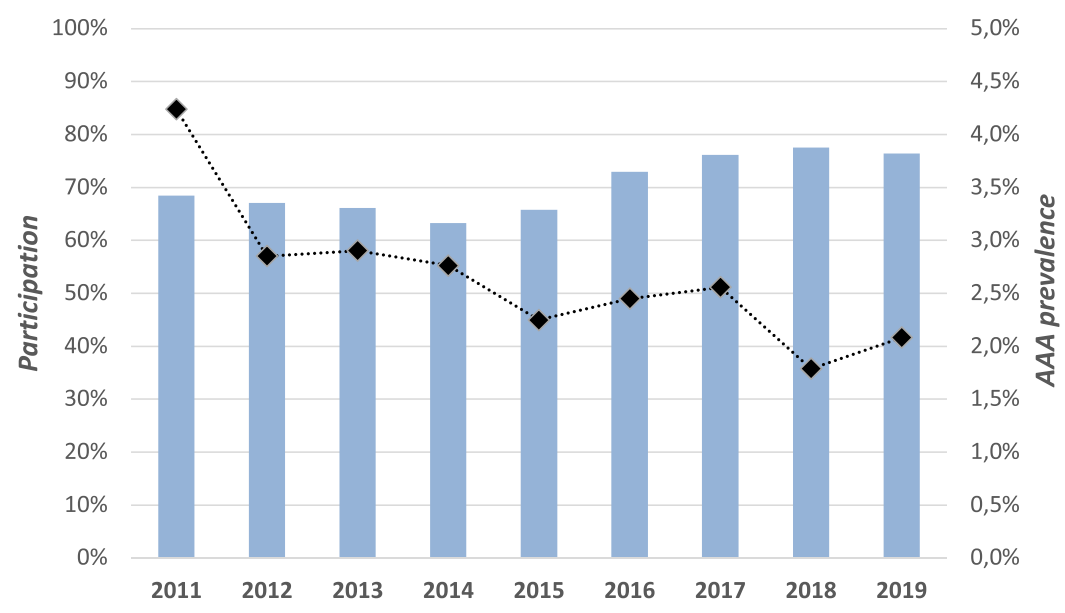

Figure 2 Yearly participation (columns) and AAA point prevalence (diamonds). 


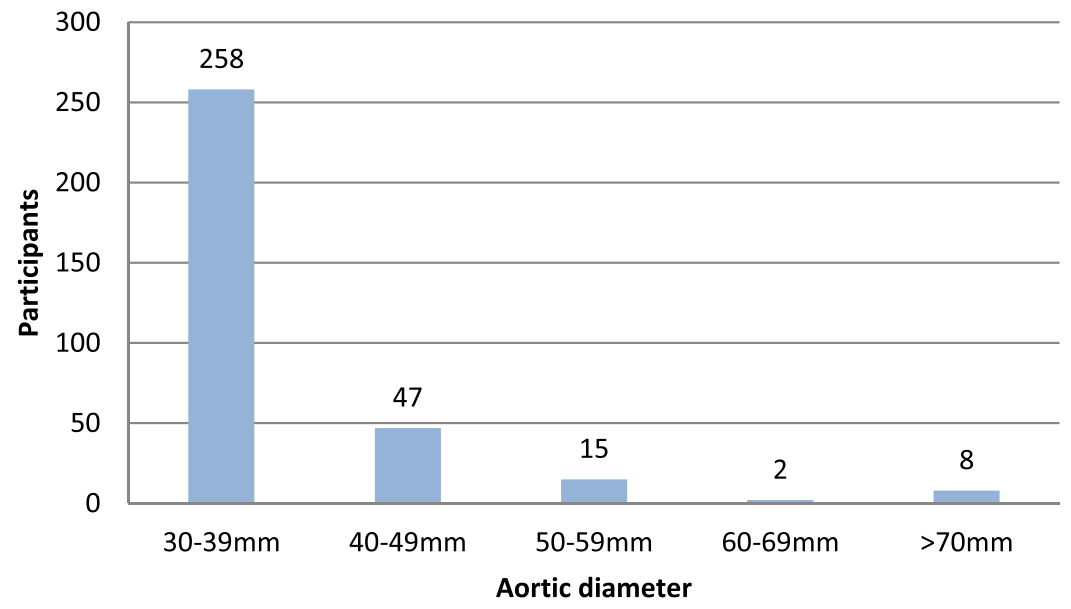

Figure 3 The distribution of aneurysms. The aneurysms are categorized by every 10 th $\mathrm{mm}, \mathrm{n}=330$.

must be taken into consideration when discussing the findings. In large screening trials, the percentage of attendance varies from $63 \%$ to $80 \%{ }^{34}$ A single re-invitation could have increased the number of participants to approximately $80 \%$ of the invited, as seen in the Swedish screening program. ${ }^{9}$

Guidelines from European Society for Vascular Surgery (ESVS) and Society for Vascular Surgery (SVS) recommend treatment for AAA at a diameter $\geq 55 \mathrm{~mm}$ in men. ${ }^{28,31}$ In this study, $6.4 \%$ of the aneurysms were $\geq 55 \mathrm{~mm}$ at the time of screening, which shows that screening for AAA in men at the age of 65 years discovers individuals in need of treatment for a potentially lethal condition. These individuals amount to $0.2 \%$ of the screened population, and demonstrate a lower incidence than what was found in the four previous large screening studies (0.4-0.6\%). ${ }^{35-37}$ Amongst the participants, $77.7 \%$ of the detected aneurysms were $<40 \mathrm{~mm}$, and this is consistent with previous data. ${ }^{27}$

Previous studies have examined the group of 65-yearold men with sub-aneurysmal aortas (25-29 $\mathrm{mm})$ and found that these men are at risk of developing AAA within 5 years. $^{23,38}$ Data from the screening program in Gloucestershire demonstrated that $28 \%$ of participants with sub-aneurysmal aortas develop AAA within 15 years. $^{23}$ In our material, $6.4 \%$ had sub-aneurysmal aortas,

Table I Descriptive Data; Risk Factors and Comorbidities

\begin{tabular}{|c|c|c|c|c|c|c|}
\hline Variable & $\begin{array}{l}\text { All Participants, } \\
n=|2,8| 10\end{array}$ & $\begin{array}{l}\text { Aortic Diameter } \geq \\
\mathbf{3 0} \mathrm{mm}, \mathbf{n}=\mathbf{3 3 0}\end{array}$ & $\begin{array}{l}\text { Aortic Diameter } \\
<30 \mathrm{~mm}, \mathrm{n}=\mid 2,480\end{array}$ & P-value* & $\begin{array}{l}\text { Aortic Diameter } \\
25-29 \mathrm{~mm}, \mathrm{n}=\mathbf{8 6 2}\end{array}$ & P-value** \\
\hline $\mathrm{BMI}>25$ & $65.5 \%$ & $75.2 \%$ & $65.3 \%$ & $<0.001$ & $70.2 \%$ & 0.01 \\
\hline $\mathrm{BMI}>30$ & $16.6 \%$ & $25.1 \%$ & $16.4 \%$ & $<0.001$ & $20.8 \%$ & $<0.001$ \\
\hline $\mathrm{ABI}<0.9$ & $6.7 \%$ & $15.5 \%$ & $6.5 \%$ & $<0.001$ & $8.2 \%$ & 0.017 \\
\hline MI & $8.6 \%$ & $20.0 \%$ & $8.3 \%$ & $<0.001$ & $8.6 \%$ & 0.377 \\
\hline TIA & $2.9 \%$ & $4.5 \%$ & $2.9 \%$ & 0.063 & $3.4 \%$ & 0.218 \\
\hline Stroke & $2.8 \%$ & $6.4 \%$ & $2.7 \%$ & $<0.001$ & $3.6 \%$ & 0.056 \\
\hline Hypertension & $40.2 \%$ & $53.0 \%$ & $39.9 \%$ & $<0.001$ & $41.5 \%$ & 0.163 \\
\hline Diabetes mellitus & $11.2 \%$ & $7.9 \%$ & $11.3 \%$ & 0.056 & $7.2 \%$ & $<0.001$ \\
\hline IC & $6.5 \%$ & $12.5 \%$ & $6.4 \%$ & $<0.001$ & $7.7 \%$ & 0.061 \\
\hline Current smoker & $16.8 \%$ & $39.7 \%$ & $16.2 \%$ & $<0.001$ & $24.0 \%$ & $<0.001$ \\
\hline Past smoker & $43.6 \%$ & $45.2 \%$ & $43.6 \%$ & 0.306 & $43.6 \%$ & 0.506 \\
\hline Family history of AAA & $8.3 \%$ & $17,3 \%$ & $8.1 \%$ & $<0.001$ & $13.5 \%$ & $<0.001$ \\
\hline Statin & $33.1 \%$ & $48.8 \%$ & $32.7 \%$ & $<0.001$ & $32.8 \%$ & 0.486 \\
\hline ASA & $24.8 \%$ & $35.9 \%$ & $24.5 \%$ & $<0.001$ & $25.9 \%$ & 0.175 \\
\hline
\end{tabular}

Notes: Statistical significance was set at $\mathrm{p}$-value $\leq 0.05$, and significant $\mathrm{p}$-values are presented in bold text. P-values are calculated for $* A$ ortic diameter $\geq 30$ mm versus aortic diameter $<30 \mathrm{~mm}$, **Aortic diameter $25-29 \mathrm{~mm}$ versus aortic diameter $<25 \mathrm{~mm}$.

Abbreviations: BMI, body mass index; $\mathrm{ABI}$, ankle brachial index; MI, myocardial infarction; TIA, transitory ischemic attack; IC, intermittent claudication; $\mathrm{ASA}$, acetylsalicylic acid. 
Table 2 Univariate Analysis

\begin{tabular}{|c|c|c|c|c|}
\hline Discrete Variables & $\begin{array}{c}\text { Number of Participants } \\
\text { with AAA }\end{array}$ & Odds Ratio & $95 \% \mathrm{Cl}$ & P-value \\
\hline Smoking & Yes/No & 3,40 & $2.7 I-4.26$ & 0.0001 \\
\hline Hypertension & Yes/No & $\mathrm{I}, 70$ & $1.30-2.12$ & 0.001 \\
\hline Diabetes mellitus & Yes/No & 0,67 & $0.45-1.01$ & 0.56 \\
\hline Continuous Variables & Number of Participants & Mean & $95 \% \mathrm{Cl}$ & P-value \\
\hline \multicolumn{5}{|l|}{ BMI } \\
\hline$A D \geq 30 \mathrm{~mm}$ & 330 & 27.6 & \pm 4.09 & \multirow[t]{2}{*}{0.0001} \\
\hline$A D<30 \mathrm{~mm}$ & 12,449 & 26.67 & \pm 4.48 & \\
\hline
\end{tabular}

Notes: Risk factors univariate analysis. Abdominal aortic aneurysm; aortic diameter $\geq 30 \mathrm{~mm}$.

Abbreviations: $\mathrm{AD}$, aortic diameter; $\mathrm{Cl}$, confidence interval; $\mathrm{BMI}$, body mass index.

Table 3 Multivariate Analysis

\begin{tabular}{|c|c|c|c|c|c|}
\hline Variable & Number & with AAA & Odds Ratio & $95 \% \mathrm{Cl}$ & P-value \\
\hline $\mathrm{BMI}>30$ & $\begin{array}{l}\text { Yes } \\
\text { No }\end{array}$ & $\begin{array}{c}330 \\
12,449\end{array}$ & 1.02 & $1.00-1.03$ & 0.0072 \\
\hline Diabetes mellitus & $\begin{array}{l}\text { Yes } \\
\text { No }\end{array}$ & $\begin{array}{c}329 \\
|2,45|\end{array}$ & 0.52 & $0.35-0.79$ & 0.0025 \\
\hline Hypertension & $\begin{array}{l}\text { Yes } \\
\text { No }\end{array}$ & $\begin{array}{c}330 \\
12,456\end{array}$ & 1.87 & $1.49-2.35$ & 0.0001 \\
\hline Smoking & $\begin{array}{l}\text { Yes } \\
\text { No }\end{array}$ & $\begin{array}{c}330 \\
12,479\end{array}$ & 3.64 & $2.90-4.58$ & 0.0001 \\
\hline
\end{tabular}

Notes: Multivariate analysis using the logistic model. Independent risk factors of abdominal aortic aneurysm; aortic diameter $\geq 30 \mathrm{~mm}$.

Abbreviation: $\mathrm{Cl}$, confidence interval.

and these participants presented some of the same risk factors as participants with AAA, such as BMI > 25, current smoking and a family history of AAA. These findings highlight a group that might benefit from followup ultrasonography.

Known risk factors for developing AAA include male sex, smoking, a family history of AAA and old age. ${ }^{18,23-}$ 25,39 Hypertension is another potential risk factor, which is also associated with an increased risk for AAA. ${ }^{18,26,31} \mathrm{We}$ found four independent risk factors for AAA: smoking, hypertension, obesity, and diabetes mellitus. These were considered as potential etiological risk factors for AAA, while the other registrations represented the presence of concomitant cardiovascular disease.

In this material, there is a significantly higher number of smokers in the AAA group (compared to participants with aortic diameter $<30 \mathrm{~mm}$ ), and in the sub-aneurysmal group (compared to participants with aortic diameter $<25 \mathrm{~mm}$ ). No such difference was found among past smokers; however, the questionnaire did not differentiate on when the participants quit smoking. Other investigators have found that current smokers have a higher risk of developing AAA than past smokers. ${ }^{10,18,35}$ Smoking has also been associated with higher aneurysm growth rate and progression of sub-aneurysmal aortas to AAAs. ${ }^{9,36,37}$ In recent recommendations published by the US Preventive Services Task Force, it is concluded that, most likely there is little benefit in screening elderly men who have never smoked. $^{40}$ In Norway, the prevalence of smokers has decreased during the last decades, according to Statistics Norway the number of daily smokers decreased from $42 \%$ to $9 \%$ during the period 1973-2020, and its effect on the future prevalence of AAA remains to be investigated. ${ }^{41}$

In this study, $53 \%$ of men with AAA reported to have hypertension, which is significantly higher than for men with aortic diameters $<30 \mathrm{~mm}(39.9 \%)$. In a systematic review and meta-analysis from 2004, Cornuz et al found a weak positive association between hypertension and 


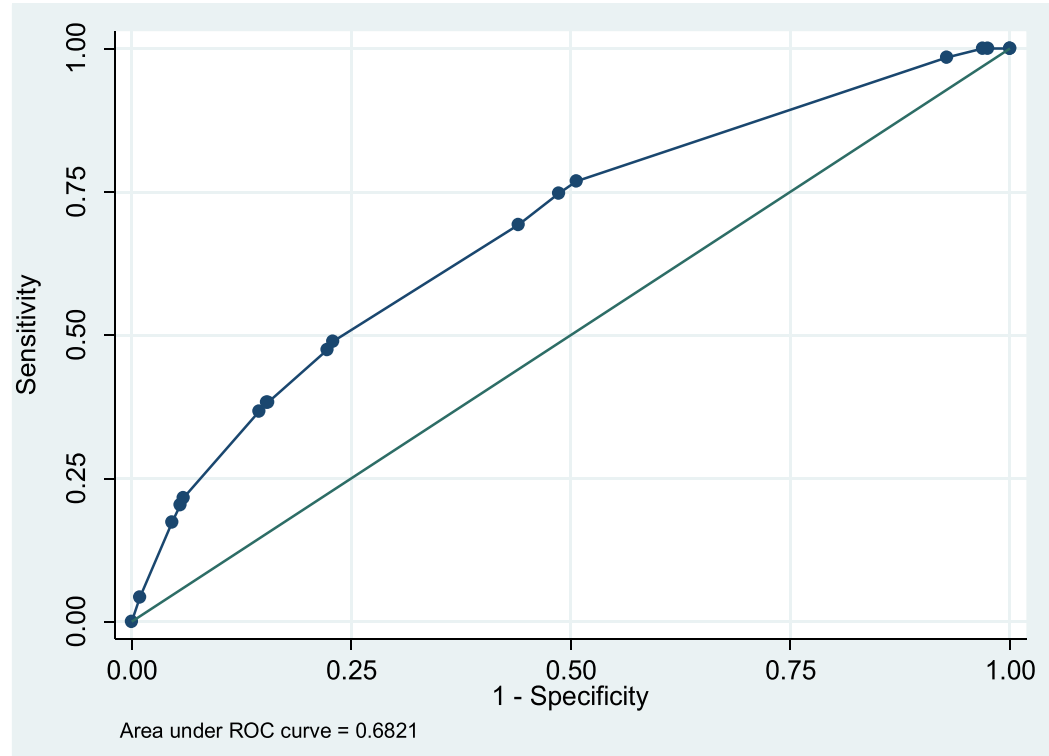

Figure 4 ROC curve. Measures the ability of the regression model to differentiate among those who have or do not have AAA. Abbreviation: ROC curve, receiver operating characteristic curve.

AAA, while a recent meta-analysis suggests that hypertension increases the risk of developing AAA by $66 \% .{ }^{42,43}$ A review by Takagi et al showed no association between hypertension and AAA growth. ${ }^{44}$

Obesity was an independent, but weak risk factor for AAA in our study. A Swedish observational cohort study did not reveal an association between BMI and AAA in men and women aged 46-84 years, but they found an increased risk of developing AAA in individuals with abdominal adiposity. ${ }^{45}$ A systematic reviews from 2013 however, suggests a positive association between BMI and $\mathrm{AAA}^{46}$

Diabetes mellitus was negatively associated with AAA. Recent meta-analyses suggest that in individuals with diabetes mellitus, the risk of developing AAA is reduced by $42 \%$, and that the AAA growth in non-diabetic patients is slower compared to patients with diabetes. ${ }^{47,48}$ The biological pathways that are considered to limit AAA growth include effect on extracellular matrix, formation of glycation end-products and reduced inflammation. Medications, such as Metformin, used to treat diabetes mellitus may also limit the progression of AAA. ${ }^{49,50}$ Moreover, diabetes mellitus is an important determinant of mortality following surgical treatment of AAA. ${ }^{51}$ An ongoing prospective multicenter study in Norway aims to investigate the relationship between glycemic status and mortality in treatment of AAA (ABANDIA).

Concomitant existence of cardiovascular disease was not surprisingly predominant in the AAA group, as AAA shares a lot of similarities with atherosclerotic disease. In this study, a significantly higher prevalence of $\mathrm{ABI}<0.9$ in the AAA group was found (compared to participants with aortic diameter $<30 \mathrm{~mm}$ ), but not in the sub-aneurysmal group (compared to participants with aortic diameter $<25 \mathrm{~mm}$ ). ABI is highly specific (99\%) and sensitive (94-97\%) for the detection of high-grade stenoses in PAD. ${ }^{30}$ In the AAA group, $12.5 \%$ reported to experience claudication, whereas only $6.4 \%$ reported this in the group with normal aortic diameter, and this corresponded to the measured ABI. It is interesting that only $15.5 \%$ of the men with AAA had an $\mathrm{ABI}<0.9$, and the prevalence of $\mathrm{ABI}<0.9$ was surprisingly low (6.7\%) among all 65-year-old men screened in Oslo. A meta-analysis from 2016 found a positive correlation between $\mathrm{PAD}$ and AAA, and a negative correlation between PAD and aneurysm growth. ${ }^{52}$ Lin et al recently published data on 6590 people with AAA, and found an increased risk of developing PAD in this cohort. ${ }^{53}$

Studies have shown a significant correlation between AAA and three-vessel coronary artery disease (CAD) ${ }^{18,54-56}$ The prevalence of AAA in patients with CAD has been reported to be higher than in the general population, and the severity of the disease seems to effect the prevalence. ${ }^{55,56}$ We find it interesting that the prevalence of MI is $20 \%$ in the AAA group in the present study, 
whereas it is $8.6 \%$ in the sub-aneurysmal group and $8.3 \%$ in the group with normal aortas.

Participants in the AAA group more often reported a history of stroke, whereas for TIA there was no significant difference. The risk factors and comorbidities were self-reported by the participants, and whether they were able to discriminate between stroke and TIA could influence these results. An association between a history of stroke and AAA in women was found by Chabok et al. ${ }^{57}$ Other investigators have also found a higher prevalence of AAA in patients with stroke or TIA. ${ }^{58,59}$

A systematic review by Fleming et al shows an increased risk of developing AAA in individuals with a family history of AAA. ${ }^{34}$ In our material, both in the AAA group and in the sub-aneurysmal group, the prevalence of a family history of AAA was significantly higher than that found in the group with aortic diameter $<30 \mathrm{~mm}$ and $<25 \mathrm{~mm}$, respectively. Unfortunately, not enough data was obtained from the participants to analyze this as a potential risk factor with regression analyses.

As participation ranged from $63.3 \%$ to $77.6 \%$ annually, the results must be interpreted with caution. We have no data on the remaining population of the invited 65-year-old men, and it would be of interest to study this group and their risk factors in the future. In addition, there are regional differences in health behavior in Norway, and the healthiest part of the population lives in the capital (Statistics Norway, survey on health 2015). Whether there are regional differences in the AAA prevalence in Norway remains to be studied.

For future similar studies, our recommendation would be to translate invitation letters to different languages addressing the increasing heterogeneous population in our society today. Moreover, a second invitation would increase participation rate. To improve the effect of screening, one could consider to include a follow-up program for all participants with AAA. This requires, however, extended resources.

\section{Conclusions}

Screening for AAA in 65-year-old men in Oslo revealed a prevalence of $2.6 \%$. In the AAA group, we found a higher prevalence of risk factors and comorbidities, such as smoking, overweight and cardiovascular disease. We found four independent risk factors for AAA: smoking, hypertension, obesity and diabetes mellitus, the last having an inverse effect. The data also suggest that people with subaneurysmal aortas are at risk of developing AAA. This highlights the potential health benefit of offering follow-up ultrasonographies to individuals in this group. Furthermore, the data indicate that individuals with certain risk factor profiles more often develop AAAs, which may give a rationale for selective, risk factor-based screening and follow-up.

\section{Data Sharing Statement}

For legal reasons, the raw data from this study cannot be shared publicly.

\section{Acknowledgments}

Professor Jorgen Jorgensen (1947-2017) is gratefully acknowledged for initiating the aorta screening project in Oslo in May 2011. We are grateful to Dr. Oyvind Risum for valuable help with regression analyses. We also thank the screening team for their efforts in inviting and examining the participants, and collecting the data.

\section{Disclosure}

The authors report no conflicts of interest in this work.

\section{References}

1. Dias-Neto M, Castro-Ferreira R, Mani K, Freitas A, Leite-Moreira A, Sampaio SM. Nationwide analysis of ruptured abdominal aortic aneurysm in Portugal (2000-2015). Eur J Vasc Endovasc Surg. 2020;60(1):27-35. doi:10.1016/j.ejvs.2020.02.024

2. Budtz-Lilly J, Björck M, Venermo M, et al. Editor's choice - The impact of centralisation and endovascular aneurysm repair on treatment of ruptured abdominal aortic aneurysms based on international registries. Eur J Vasc Endovasc Surg. 2018;56(2):181-188. doi:10. 1016/j.ejvs.2018.01.014

3. Powell JT, Sweeting MJ, Thompson MM, et al. Endovascular or open repair strategy for ruptured abdominal aortic aneurysm: 30 day outcomes from IMPROVE randomised trial. BMJ. 2014;348(1):f7661. doi:10.1136/bmj.f7661

4. Briggs CS, Sibille JA, Yammine H, et al. Short-term and midterm survival of ruptured abdominal aortic aneurysms in the contemporary endovascular era. J Vasc Surg. 2018;68(2):408e1-414e1. doi:10.10 16/j.jvs.2017.12.037

5. Roosendaal LC, Kramer GM, Wiersema AM, Wisselink W, Jongkind V. Outcome of ruptured abdominal aortic aneurysm repair in octogenarians: a systematic review and meta-analysis. Eur $J$ Vasc Endovasc Surg. 2020;59(1):16-22. doi:10.1016/j.ejvs.2019.07.014

6. Ammar AD. Mortality for open abdominal aortic aneurysm repair before and after Endovascular Aortic Repair (EVAR). Am Surg. 2019;85(12):1341-1344. doi:10.1177/000313481908501226

7. Qadura M, Pervaiz F, Harlock JA, et al. Mortality and reintervention following elective abdominal aortic aneurysm repair. J Vasc Surg. 2013;57(6):1676-1683, 1683.e1. doi:10.1016/j.jvs.2013.02.013

8. Beck AW, Goodney PP, Nolan BW, Likosky DS, Eldrup-Jorgensen J, Cronenwett JL. Predicting 1-year mortality after elective abdominal aortic aneurysm repair. $J$ Vasc Surg. 2009;49(4):838-843; discussion 843-844. doi:10.1016/j.jvs.2008.10.067

9. Wanhainen A, Hultgren R, Linné A, et al. Outcome of the Swedish nationwide abdominal aortic aneurysm screening program. Circulation. 2016;134(16):1141-1148. doi:10.1161/CIRCULATIONAHA.116.022 305

10. Cosford PA, Leng GC. Screening for abdominal aortic aneurysm. Cochrane Database Syst Rev. 2007;(2):CD002945. doi:10.1002/ 14651858.CD002945.pub2 
11. Guirguis-Blake JM, Beil TL, Senger CA, Coppola EL. Primary care screening for abdominal aortic aneurysm: updated evidence report and systematic review for the US preventive services task force. JAMA. 2019;322(22):2219-2238. doi:10.1001/jama.2019.17 021

12. Ali MU, Fitzpatrick-Lewis D, Miller J, et al. Screening for abdominal aortic aneurysm in asymptomatic adults. J Vasc Surg. 2016;64 (6):1855-1868. doi:10.1016/j.jvs.2016.05.101

13. Ali MU, Fitzpatrick-Lewis D, Kenny M, Miller J, Raina P, Sherifali D. A systematic review of short-term vs long-term effectiveness of one-time abdominal aortic aneurysm screening in men with ultrasound. J Vasc Surg. 2018;68(2):612-623. doi:10.1016/j. jvs.2018.03.411

14. Takagi H, Goto S, Matsui M, Manabe H, Umemoto T. A further meta-analysis of population-based screening for abdominal aortic aneurysm. J Vasc Surg. 2010;52(4):1103-1108. doi:10.1016/j. jvs.2010.02.283

15. Thompson SG, Ashton HA, Gao L, Buxton MJ, Scott RAP. Final follow-up of the Multicentre Aneurysm Screening Study (MASS) randomized trial of abdominal aortic aneurysm screening. $\mathrm{Br}$ J Surg. 2012;99(12):1649-1656. doi:10.1002/bjs.8897

16. Davis M, Harris M, Earnshaw JJ. Implementation of the national health service abdominal aortic aneurysm screening program in England. J Vasc Surg. 2013;57(5):1440-1445. doi:10.1016/j.jvs.20 12.10.114

17. Chun KC, Dolan KJ, Smothers HC, et al. The 10-year outcomes of a regional abdominal aortic aneurysm screening program. $J$ Vasc Surg. 2019;70(4):1123-1129. doi:10.1016/j.jvs.2019.01.053

18. Kent KC, Zwolak RM, Egorova NN, et al. Analysis of risk factors for abdominal aortic aneurysm in a cohort of more than 3 million individuals. $J$ Vasc Surg. 2010;52(3):539-548. doi:10.1016/j. jvs.2010.05.090

19. Lederle FA, Johnson GR, Wilson SE, et al. Prevalence and associations of abdominal aortic aneurysm detected through screening. Aneurysm Detection and Management (ADAM) veterans affairs cooperative study group. Ann Intern Med. 1997;126(6):441-449. doi:10.7326/0003-4819-126-6-199703150-00004

20. Newman AB, Arnold AM, Burke GL, O'Leary DH, Manolio TA. Cardiovascular disease and mortality in older adults with small abdominal aortic aneurysms detected by ultrasonography: the cardiovascular health study. Ann Intern Med. 2001;134(3):182-190. doi:10.7326/0003-4819-134-3-200102060-00008

21. Collin J, Araujo L, Walton J, Lindsell D. Oxford screening programme for abdominal aortic aneurysm in men aged 65 to 74 years. Lancet Lond Engl. 1988;2(8611):613-615. doi:10.1016/s01406736(88)90649-6

22. Chichester Aneurysm Screening Group, Viborg Aneurysm Screening Study, Western Australian Abdominal Aortic Aneurysm Program. A comparative study of the prevalence of abdominal aortic aneurysms in the United Kingdom, Denmark, and Australia. J Med Screen. 2001;8(1):46-50. doi:10.1136/jms.8.1.46.

23. Oliver-Williams C, Sweeting MJ, Turton G, et al. Lessons learned about prevalence and growth rates of abdominal aortic aneurysms from a 25-year ultrasound population screening programme. $\mathrm{Br}$ J Surg. 2018;105(1):68-74. doi:10.1002/bjs.10715

24. Krohn CD, Kullmann G, Kvernebo K, Rosén L, Kroese A. Ultrasonographic screening for abdominal aortic aneurysm. Eur J Surg Acta Chir. 1992;158(10):527-530.

25. Singh K, Bønaa KH, Jacobsen BK, Bjørk L, Solberg S. Prevalence of and risk factors for abdominal aortic aneurysms in a population-based study: the Tromsø Study. Am J Epidemiol. 2001;154(3):236-244. doi:10.1093/aje/154.3.236

26. Forsdahl SH, Singh K, Solberg S, Jacobsen BK. Risk factors for abdominal aortic aneurysms: a 7-year prospective study: the Tromsø Study, 1994-2001. Circulation. 2009;119(16):2202-2208. doi:10.11 61/CIRCULATIONAHA.108.817619
27. Guirguis-Blake JM, Beil TL, Senger CA, Whitlock EP. Ultrasonography screening for abdominal aortic aneurysms: a systematic evidence review for the U.S. preventive services task force. Ann Intern Med. 2014;160(5):321-329. doi:10.7326/M13-1844

28. Chaikof EL, Dalman RL, Eskandari MK, et al. The society for vascular surgery practice guidelines on the care of patients with an abdominal aortic aneurysm. J Vasc Surg. 2018;67(1):2e2-77.e2. doi:10.1016/j.jvs.2017.10.044

29. Watson JDB, Gifford SM, Bandyk DF. Aortic aneurysm screening using duplex ultrasound: choosing wisely who to examine. Semin Vasc Surg. 2020;33(3-4):54-59. doi:10.1053/j.semvascsurg.2020.05.002

30. Wanhainen A, Verzini F, Van Herzeele I, et al. Editor's choice - European Society for Vascular Surgery (ESVS) 2019 clinical practice guidelines on the management of abdominal aorto-iliac artery aneurysms. Eur $J$ Vasc Endovasc Surg. 2019;57(1):8-93. doi:10.1016/j.ejvs.2018.09.020

31. Aboyans V, Ricco J-B, Bartelink M-LE-L, et al. Editor's choice 2017 ESC guidelines on the diagnosis and treatment of peripheral arterial diseases, in collaboration with the European Society for Vascular Surgery (ESVS). Eur J Vasc Endovasc Surg. 2018;55 (3):305-368. doi:10.1016/j.ejvs.2017.07.018

32. Kleinbaum DG, Kupper LL,Morgenstern H. Epidemiologic Research: Principles and Quantitative Methods. John Wiley and Sons. 1982

33. Scott RA, Ashton HA, Kay DN. Abdominal aortic aneurysm in 4237 screened patients: prevalence, development and management over 6 years. Br J Surg. 1991;78(9):1122-1125. doi:10.1002/bjs.1800780929

34. Fleming C, Whitlock EP, Beil TL, Lederle FA. Screening for abdominal aortic aneurysm: a best-evidence systematic review for the U.S. Preventive Services Task Force. Ann Intern Med. 2005;142 (3):203-211. doi:10.7326/0003-4819-142-3-200502010-00012

35. Ashton HA, Buxton MJ, Day NE, et al. The Multicentre Aneurysm Screening Study (MASS) into the effect of abdominal aortic aneurysm screening on mortality in men: a randomised controlled trial. Lancet Lond Engl. 2002;360(9345):1531-1539. doi:10.1016/s01406736(02)11522-4

36. Lindholt JS, Juul S, Fasting H, Henneberg EW. Screening for abdominal aortic aneurysms: single centre randomised controlled trial. $B M J$. 2005;330(7494):750. doi:10.1136/bmj.38369.620162.82

37. Norman PE, Jamrozik K, Lawrence-Brown MM, et al. Population based randomised controlled trial on impact of screening on mortality from abdominal aortic aneurysm. BMJ. 2004;329(7477):1259. doi:10.1136/bmj.38272.478438.55

38. Svensjö S, Björck M, Wanhainen A. Editor's choice: five-year outcomes in men screened for abdominal aortic aneurysm at 65 years of age: a population-based cohort study. Eur J Vasc Endovasc Surg. 2014;47(1):37-44. doi:10.1016/j.ejvs.2013.10.007

39. Benson RA, Poole R, Murray S, Moxey P, Loftus IM. Screening results from a large United Kingdom abdominal aortic aneurysm screening center in the context of optimizing United Kingdom national Abdominal Aortic Aneurysm Screening Programme protocols. J Vasc Surg. 2016;63 (2):301-304. doi:10.1016/j.jvs.2015.08.091

40. Owens DK, Davidson KW, Krist AH, et al. Screening for abdominal aortic aneurysm: US preventive services task force recommendation statement. JAMA. 2019;322(22):2211-2218. doi:10.1001/jama.2019.18928

41. Percentage daily smokers and occasional smokers, by sex and age (per cent) 1973-2020. Statistics Norway; October 6, 2021. Available from: https://www.ssb.no/en/statbank/table/05307/. Accessed August 11, 2021.

42. Cornuz J, Sidoti Pinto C, Tevaearai H, Egger M. Risk factors for asymptomatic abdominal aortic aneurysm: systematic review and meta-analysis of population-based screening studies. Eur J Public Health. 2004;14(4):343-349. doi:10.1093/eurpub/14.4.343

43. Kobeissi E, Hibino M, Pan H, Aune D. Blood pressure, hypertension and the risk of abdominal aortic aneurysms: a systematic review and meta-analysis of cohort studies. Eur J Epidemiol. 2019;34 (6):547-555. doi:10.1007/s10654-019-00510-9 
44. Takagi H, Umemoto T. Association of hypertension with abdominal aortic aneurysm expansion. Ann Vasc Surg. 2017;39:74-89. doi:10. 1016/j.avsg.2016.04.019

45. Stackelberg O, Björck M, Sadr-Azodi O, Larsson SC, Orsini N, Wolk A. Obesity and abdominal aortic aneurysm. Br J Surg. 2013;100(3):360-366. doi:10.1002/bjs.8983

46. Cronin O, Walker PJ, Golledge J. The association of obesity with abdominal aortic aneurysm presence and growth. Atherosclerosis. 2013;226(2):321-327. doi:10.1016/j.atherosclerosis.2012.10.041

47. Aune D, Schlesinger S, Norat T, Riboli E. Diabetes mellitus and the risk of abdominal aortic aneurysm: a systematic review and meta-analysis of prospective studies. J Diabetes Complications. 2018;32(12):1169-1174. doi:10.1016/j.jdiacomp.2018.09.009

48. Takagi H, Umemoto T. Diabetes and abdominal aortic aneurysm growth. Angiology. 2016;67(6):513-525. doi:10.1177/ 0003319715602414

49. Dattani N, Sayers RD, Bown MJ. Diabetes mellitus and abdominal aortic aneurysms: a review of the mechanisms underlying the negative relationship. Diab Vasc Dis Res. 2018;15(5):367-374. doi:10. $1177 / 1479164118780799$

50. Golledge J, Moxon J, Pinchbeck J, et al. Association between metformin prescription and growth rates of abdominal aortic aneurysms. Br J Surg. 2017;104(11):1486-1493. doi:10.1002/bjs.10587

51. Hjellestad ID, Søfteland E, Nilsen RM, Husebye ES, Jonung T. Abdominal aortic aneurysms-glycaemic status and mortality. J Diabetes Complications. 2016;30(3):438-443. doi:10.1016/j.jdiacomp.2015.12. 015

52. Takagi H, Umemoto T. Association of peripheral artery disease with abdominal aortic aneurysm growth. J Vasc Surg. 2016;64 (2):506-513. doi:10.1016/j.jvs.2016.01.059
53. Lin Y-T, Chen H-J, Chen P-C, Sung F-C. Increased risk of peripheral arterial disease in patients with abdominal aortic aneurysm: a retrospective cohort study (version 5). Angiology. 2019;70 (1):41-46. doi:10.1177/0003319718757615

54. Koshty A, Bork M, Böning A, Gündüz D, Pleger SP. Coronary artery disease as a relevant risk factor in screening of abdominal aortic ectasia and aneurysm. Thorac Cardiovasc Surg. 2021;69(1):57-62. doi: $10.1055 / \mathrm{s}-0038-1676336$

55. Reutersberg B, Salvermoser M, Haller B, et al. Screening cardiovascular patients for aortic aneurysms (SCAN) - high prevalence of abdominal aortic aneurysms in coronary heart disease patients requiring intervention. VASA Z Gefasskrankheiten. 2020;49(5):375-381. doi:10.1024/0301-1526/a000881

56. Hernesniemi JA, Vänni V, Hakala T. The prevalence of abdominal aortic aneurysm is consistently high among patients with coronary artery disease. J Vasc Surg. 2015;62(1):232-240.e3. doi:10.1016/j. jvs.2015.02.037

57. Chabok M, Nicolaides A, Aslam M, et al. Risk factors associated with increased prevalence of abdominal aortic aneurysm in women. Br J Surg. 2016;103(9):1132-1138. doi:10.1002/bjs.10179

58. van Lindert NHA, Bienfait HP, Gratama JWC, et al. Screening for aneurysm of the abdominal aorta: prevalence in patients with stroke or TIA. Eur J Neurol. 2009;16(5):602-607. doi:10.1111/j.14681331.2009.02550.x

59. Vänni V, Turtiainen J, Kaustio U, Toivanen J, Rusanen M, Hernesniemi J. Prospective ultrasound screening of men with cerebrovascular disease for abdominal aortic aneurysms. Scand J Surg. 2020. doi:10.1177/1457496920917269
Vascular Health and Risk Management

\section{Publish your work in this journal}

Vascular Health and Risk Management is an international, peerreviewed journal of therapeutics and risk management, focusing on concise rapid reporting of clinical studies on the processes involved in the maintenance of vascular health; the monitoring, prevention and treatment of vascular disease and its sequelae; and the involvement

\section{Dovepress}

of metabolic disorders, particularly diabetes. This journal is indexed on PubMed Central and MedLine. The manuscript management system is completely online and includes a very quick and fair peerreview system, which is all easy to use. Visit http://www.dovepress. com/testimonials.php to read real quotes from published authors. 